\title{
Biochemical Profile by GC-MS of Fungal Biomass Produced from the Ascospores of Tirmania nivea as a Natural Renewable Resource
}

\author{
Jamal M. Khaled ${ }^{1, *}$, Naiyf S. Alharbi ${ }^{1}$, Ramzi A. Mothana ${ }^{2}{ }^{\circledR}$, Shine Kadaikunnan ${ }^{1}$ and Ahmed S. Alobaidi ${ }^{1}$ \\ 1 Department of Botany and Microbiology, College of Science, King Saud University, Riyadh 11451, \\ Saudi Arabia; nalharbi1@ksu.edu.sa (N.S.A.); sshine@ksu.edu.sa (S.K.); ahalobaidi@ksu.edu.sa (A.S.A.) \\ 2 Department of Pharmacognosy, College of Pharmacy, King Saud University, Riyadh 11451, Saudi Arabia; \\ rmothana@ksu.edu.sa \\ * Correspondence: gkhaled@ksu.edu.sa
}

check for updates

Citation: Khaled, J.M.; Alharbi, N.S.; Mothana, R.A.; Kadaikunnan, S.; Alobaidi, A.S. Biochemical Profile by GC-MS of Fungal Biomass Produced from the Ascospores of Tirmania nivea as a Natural Renewable Resource. J. Fungi 2021, 7, 1083. https://doi.org/ $10.3390 /$ jof7121083

Academic Editors: Sengottayan Senthil-Nathan and Jae Su Kim

Received: 1 November 2021 Accepted: 13 December 2021 Published: 17 December 2021

Publisher's Note: MDPI stays neutral with regard to jurisdictional claims in published maps and institutional affiliations.

Copyright: (c) 2021 by the authors. Licensee MDPI, Basel, Switzerland. This article is an open access article distributed under the terms and conditions of the Creative Commons Attribution (CC BY) license (https:// creativecommons.org/licenses/by/ $4.0 /)$.

\begin{abstract}
The edible fruiting bodies of desert truffles are seasonally collected and consumed in many regions of the world. Although they are very expensive, they are bought and sold as a result of considerable scientific reports confirming their health and nutritional benefits. This study aimed to conduct laboratory production of the fungal biomass of Tirmania nivea as a natural renewable resource of many active biological compounds using an artificial growth medium. The T. nivea collected from Hafar Al-Batin, which is north of Saudi Arabia, and their ascospores were harvested and used to produce fungal biomass in potato dextrose broth. The cultivation was conducted using a shaking incubator at $25^{\circ} \mathrm{C}$ for two weeks at $200 \mathrm{rpm}$. The crud extracts of the fungal biomass and mycelium-free broth were prepared using ethyl acetate, methanol and hexane. Preliminary gas chromatography-mass spectrometry (GC-MS) analysis and their biological activity as antimicrobial agents were investigated. The results showed that the crude extracts have biological activity against mold, yeast and bacteria. The preliminary GC-MS analysis reported that the fungal biomass and extracellular metabolites in the growth medium are industrial renewable resources of several biological compounds that could be used as antifungal, antibacterial, antiviral, anticancer, antioxidant, anti-trypanosomal and anti-inflammatory agents.
\end{abstract}

Keywords: GC-MS analysis; Tirmania nivea; antimicrobial; anticancer; production

\section{Introduction}

Tirmania nivea, which is locally called zubaidi, fagaa or kma'at, is an edible hypogenous fungal fruiting body. From a taxonomic point of view, the genus Tirmania belongs to the family Terfeziaceae and the order Pezizales. T. nivea is collected seasonally from several desert environments, including Saudi Arabia's desert. It is consumed because of its distinctive flavor and nutrient value, and it is relatively expensive due to its natural and seasonal growth associated with specific conditions and limited environments [1,2].

Generally, desert edible fungal fruiting bodies are ethnopharmacologically used to treat eye infections and fatigue, as well as promote fertility in men [3]. Chemical analysis showed that $100 \mathrm{~g}$ of a dry fruiting body of $T$. nivea consisted of fat, protein, carbohydrates and ash at 6.78, 28.8., 57.8 and 5/100 g, respectively; ascorbic acid, carotenoids and anthocyanins at 10.6, 1.1 and 29.1/100 g; and minerals such as potassium, calcium, magnesium, iron, sodium, phosphate, manganese and copper [4].

The major volatile organic compounds of the ascocarp of T. nivea include unsaturated fatty acids and hexa-decanoic acid [5]. Antioxidant chemicals extracted from the fruiting body of T. nivea vary according to its natural source. Generally, it contains anthocyanins, ascorbic acid, phenolics, flavonoids and carotenoids [6]. Aside from using truffles as food, many studies have proven that they are an important source of biological compounds, 
such as antioxidant, antibacterial, antifungal, antiviral, hepato-preservative, anticancer and anti-inflammatory agents [7]. A crude ethyl acetate extract obtained from T. pinoyi showed biological activity as an antimicrobial agent against Enterococcus sp., Staphylococcus aureus, Bacillus subtilis, Pseudomonas aeruginosa and Escherichia coli [8]. Some alcoholic extracts produced from the ascocarp of T. nivea and Terfezia claveryi showed biological activity against the human liver cancer cell line HepG2 [9]. The aqueous extracts of some desert truffles could be used to produce nanoparticles, which could be introduced in some applications [10].

Ultra-high performance liquid chromatography coupled with mass spectrometry (UPLC-MS) is used to analyze fruiting bodies of T. nivea and T. claveryi. It was reported that $T$. nivea and T. claveryi fruiting bodies contain behenic acid, resveratrol, margaric acid, naringenin, oleic acid, and lauric acid and that the highest hit bio-compounds related to anti-inflammatory targets [11]. The fruiting bodies of these truffles have a distinctive aroma because they contain significant volatile bio-compounds such as esters, alcohols, aldehydes, ketones, and sulfurs. Their therapeutic features involve their biological activity as antioxidants, antiviral, antimicrobial, hepatoprotective, and inflammatory agents. The major bio-compounds responsible for curative properties include phytosterols, N-arachidonoylethanolamine (anandamide), phenolics, and steroidal glycosides (tuberoside) [12].

Although there have been successful attempts to cultivate some types of desert truffle, such as T. claveryi [13], there are many challenges related to climatic conditions and weather effects. Given the high yields of mycelia that can be produced in a laboratory, this work was designed to produce mycelia of T. nivea using artificial media in the laboratory and to perform a gas chromatography-mass spectrometry (GC-MS) analysis of several alcoholic extracts to determine the active biological compounds from the produced mycelia.

\section{Methodology}

\subsection{Sample Collection}

Edible desert truffles (T. nivea) were collected from Hafar Al-Bati, which is north of Saudi Arabia (coordinates: $28^{\circ} 26^{\prime} 3^{\prime \prime}$ N 45 $57^{\prime} 49^{\prime \prime}$ E), between 1 March and 30 April 2021. The samples were immediately transferred using iceboxes to the Microbiology Laboratory, Botany and Microbiology Department, College of Science, King Saud University, Riyadh, Saudi Arabia. The morphological features of the samples were recorded, and the samples were washed three times using water. The external surface of the samples was sterilized three times using an ethanol solution (70\% ethanol), and then the samples were washed three times using sterile water. The samples were put in sterile plastic boxes and preserved at $-20{ }^{\circ} \mathrm{C}$ until further analysis.

\subsection{Macroscopic and Microscopic Study}

Morphological characteristics of sporocarp (fruiting body) and ascospore were recorded. A thin layer of the internal part of the samples was examined using digital light microscopy (Motic plus $2 \mathrm{ML}$, Xiamen, China) without using any stains and with lactophenol cotton blue stain (Sigma-Aldrich, St. Louis, MO, USA). The characteristics of the asci and ascospores were recorded. Colony characteristics grown from the ascospores were studied on potato dextrose agar (PDA) (Oxoid Ltd., Basingstoke, UK) after incubation at $25{ }^{\circ} \mathrm{C}$ for $48 \mathrm{~h}$. then the fungal hyphae were examined using light microscopy.

\subsection{Mycelia Production}

The spore suspension was formulated from the internal part of the sample prepared, as mentioned above. The internal part of the sample was vigorously crushed, and centrifugation (Universal 320, Hettich, Zentrifugen, Germany) was conducted at $3000 \times g$ for $10 \mathrm{~min}$. The supernatant was collected, and a direct microscopic count using Petroff-Hausser counting chambers and a standard plate count using the pour plate method were used to count and determine the viability of the ascospores. The mycelia of T. nivea were produced from the ascospore suspension using potato dextrose broth (Oxoid Ltd., Basingstoke, UK) (0.4 g 
of potato extract produced from $20 \mathrm{~g}$ of infused potato and $2 \mathrm{~g}$ of dextrose per $100 \mathrm{~mL}$ of distilled water) at $25^{\circ} \mathrm{C}$ for two weeks at $200 \mathrm{rpm}$ (IKA ${ }^{\circledR} \mathrm{KS} 4000$ i control, Staufen, Germany). Mycelia were collected from the broth using centrifugation at $2000 \times g$ for $10 \mathrm{~min}$. The collected mycelia were washed three times using sterile normal saline solution ( $0.89 \%$ sodium chloride). The wet biomass was collected, and the yield ( $\mathrm{g}$ of wet biomass per $100 \mathrm{~mL}$ of the medium used for cultivating the mycelium of T. nivea) was calculated.

\subsection{Alcoholic Extracts}

The production of crude alcoholic extracts was performed using methanol (SigmaAldrich, USA), ethyl acetate and hexane (Avonchem, Macclesfield, UK), and n-hexane (Sigma-Aldrich, St. Louis, MO, USA). Exactly $100 \mathrm{~mL}$ of the mycelium-free broth or $10 \mathrm{~g}$ of wet mycelial biomass was extracted by $100 \mathrm{~mL}$ of solvent through the maceration method at room temperature using a shaking incubator at $200 \mathrm{rpm}$ (IKA ${ }^{\circledR} \mathrm{KS} 4000 \mathrm{i}$ control, Staufen, Germany). The extraction was repeated three times, and a fresh solvent was used each time. The crude extracts were filtered, and the solvent was removed using a rotary evaporator (IKA ${ }^{\circledR}$ Rv 10, Staufen, Germany).

\subsection{GC-MS Analysis}

Agilent GC 7890A jointed with a triple-axis detector 5975 C single quadrupole mass spectrometer were used for GC-MS analysis. The column of chromatographic was an Agilent HP 5MS column ( $30 \mathrm{~m} \times 0.25 \mathrm{~mm} \times 0.25 \mu \mathrm{m}$ film thickness), with gas carrier (highpurity helium, at a flow rate of $1 \mathrm{~mL} / \mathrm{min}$ ). The temperature of the injector was $280^{\circ} \mathrm{C}$ and it was equipped with a splitless injector at 20:1. The temperatures were set at $230^{\circ} \mathrm{C}$ and $150{ }^{\circ} \mathrm{C}$ for the source temperature of MS and the Quad temperature, respectively. The initial oven temperature was $40^{\circ} \mathrm{C}$ for $1 \mathrm{~min}$, then it was increased to $150{ }^{\circ} \mathrm{C}$ at $10^{\circ} \mathrm{C} \mathrm{min}{ }^{-1}$ for $1 \mathrm{~min}$, increasing further to $300{ }^{\circ} \mathrm{C}$ at $10^{\circ} \mathrm{C} \mathrm{min}-1$ for $1 \mathrm{~min}$. The scanning range was set at 40 to 600 mass ranges at $70 \mathrm{eV}$ electron energy with solvent holdback of $3 \mathrm{~min}$. Eventually, unknown compounds were identified by comparing the spectra with those of the NIST 2008 (National Institute of Standard and Technology library). The single sample analysis was $29 \mathrm{~min}$ as required total time for analysis.

\subsection{Biological Activity of Crude Alcoholic Extracts}

The preliminary biological activity of the crude extracts against bacteria, mold and yeast was tested using a disk diffusion assay. A 6-mm sterile disk was loaded with $4 \mathrm{mg}$ of the crude extract, and the test protocol was followed according to the studies of Desbois and Smith [14] and Khadka et al. [15] using E. coli ATCC 25922, S. aureus ATCC 29213, Candida albicans ATCC 60193 and Aspergillus niger Wild strain.

\section{Results}

\subsection{Macroscopic and Microscopic Characteristics}

T. nivea has a white edible fruiting body with a size that can sometimes reach more than $10 \mathrm{~cm}$. The white color of the fruiting body changes to dark yellow over time as a result of exposure to air. The amyloid ascus of T. nivea has an ellipsoid shape, with eight smooth ascospores (Figure 1). Figure 2 shows the morphological culture and microscopic characteristics of colony produced from T. nivea ascospores on PDA. Hairy white colonies $(2.5 \mathrm{~cm}$ in size) after incubation for $48 \mathrm{~h}$, with a light black center and light yellow pigment, can be shown in the reverse view of the colony. The diameter of the septate-hyphae is approximately $4 \mu \mathrm{m}$. 

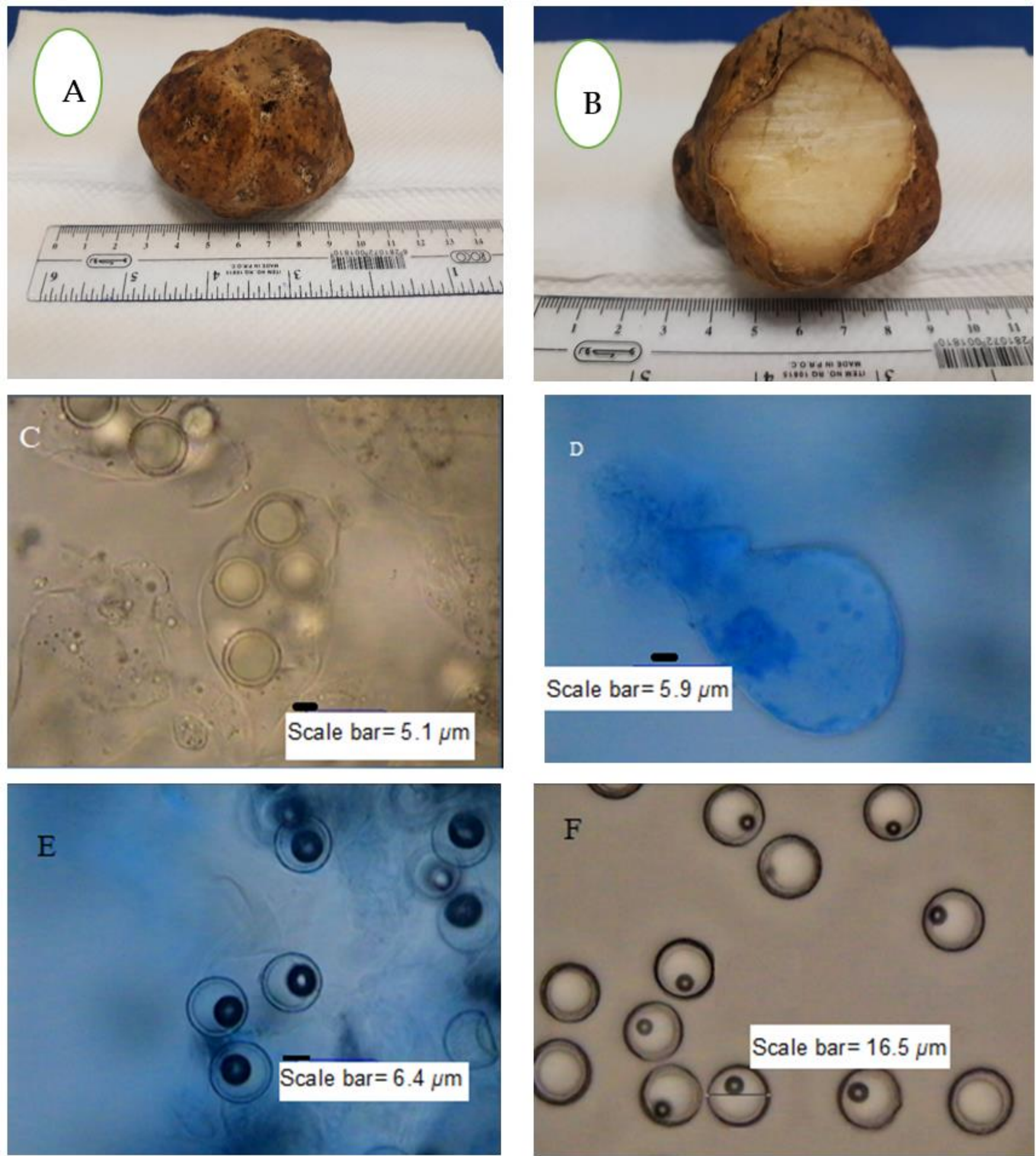

Figure 1. Macroscopic and microscopic features of T. nivea. (A) Whole fruiting body, (B) sporocarp (fruiting body) internal view, (C) ascus with aeciospores, (D) ascospore-free ascus stained with lactophenol cotton blue, (E) free ascospores strained with lactophenol cotton blue and (F) free ascospores without stain. 


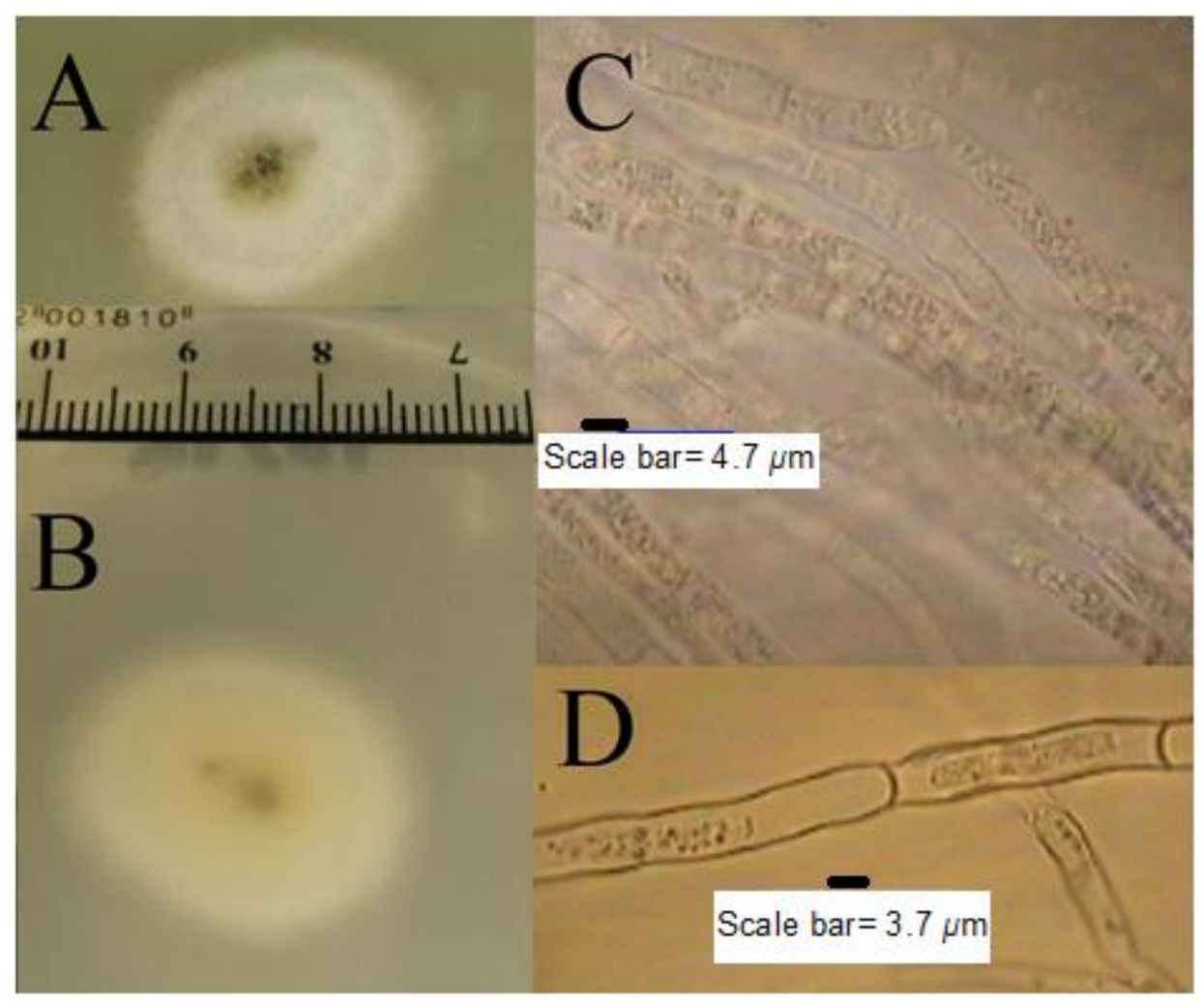

Figure 2. Morphological culture and microscopic features of colony produced from T. nivea ascospores on PDA after incubation $48 \mathrm{~h}$ at $25 \pm 1{ }^{\circ} \mathrm{C}$. (A) Front view of the colony, (B) reverse view of the colony, and (C,D), microscopic view of septate-hyphae without staining.

\subsection{Mycelial Biomass Production}

The ascospores of $T$. nivea can be cultivated on potato dextrose broth to produce a spherical mass of mycelium (Figure 3A). The morphological characteristics of the biomass produced from laboratory cultivation are shown in Figure 3B. The yield ( $\mathrm{g}$ of biomass $/ 100 \mathrm{~mL}$ of broth) was $6 \pm 1(\mathrm{~N}=3)$.

\subsection{GC-MS Analysis of Crud Extracts}

The GC-MS analysis of crude methanol, ethyl acetate and hexane extracts obtained from the wet mycelial biomass was performed to screen the active biological compounds that could be produced from the mycelium. The results showed that the crude ethyl acetate, methanol and hexane extracts could be renewable resources of many biological compounds (Tables 1-6). The results showed that the crude extracts are sources of many important compounds such as hexanal, dodecane, 4-hydroxyphenylacetic acid, heptadecane, 1-eicosene, hexa-decanoic acid-methyl ester, 7-pentadecyne, phenol, 2,4-bis(1,1-dimethylethyl), methyl palmitate, methyl linolelaidate, methyl oleate, methyl stearate, 9,12-Octadecadienoic acid (Z,Z)-, heptadecane, 1-octadecene, 5-hydroxymaltol, 11-dodecen-1-ol trifluoroacetate, and other compounds of medicinal and industrial importance listed in the tables. 


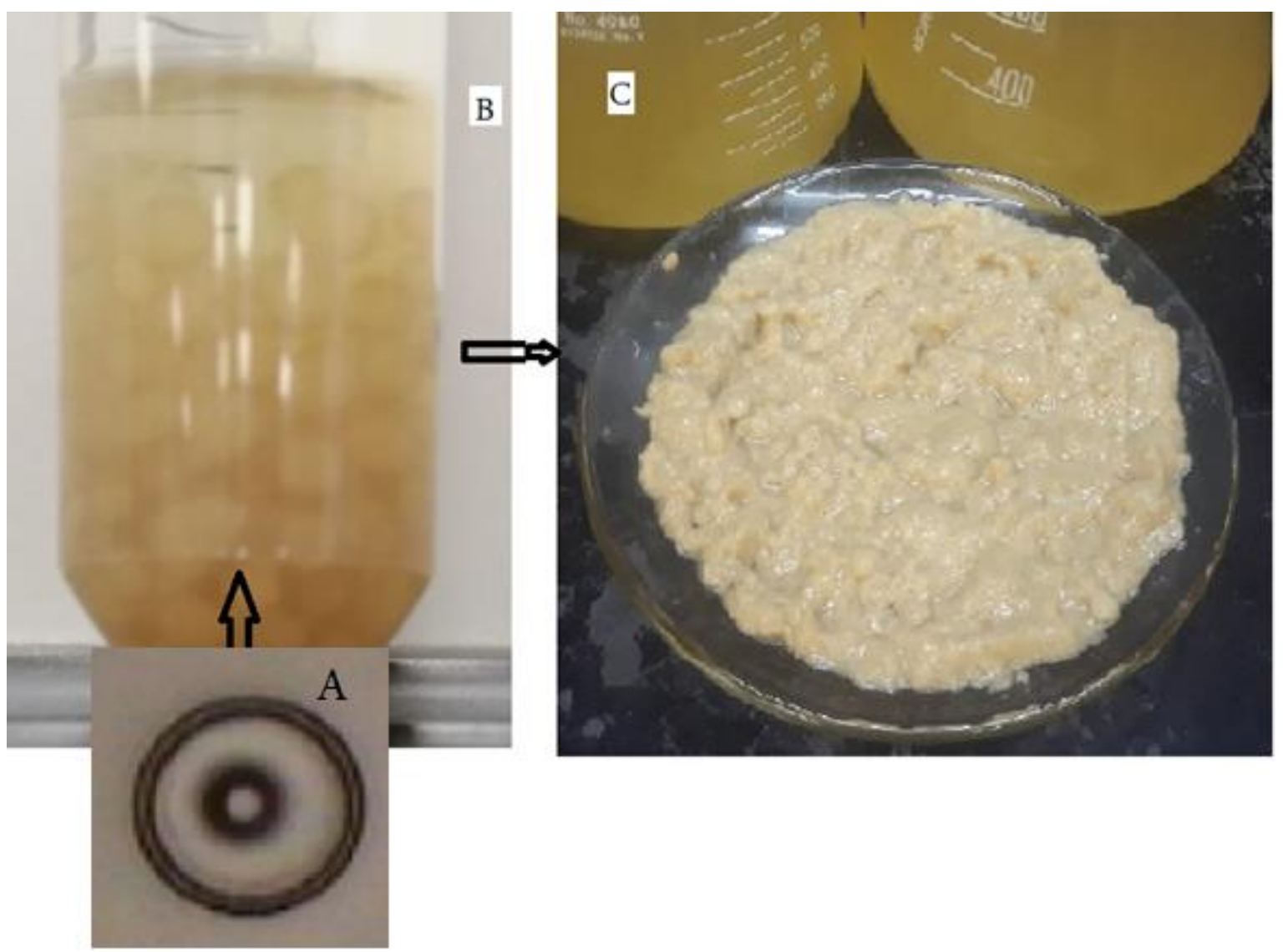

Figure 3. Mycelium and biomass produced on potato dextrose broth at $25{ }^{\circ} \mathrm{C}$ for two weeks using a shaking incubator at $200 \mathrm{rpm}$. (A) single ascospore of T. nivea (Spore diameter is equivalent to $16.5 \mu \mathrm{m}$ ), (B) type of mycelia produced on the growth medium, and (C) wet biomass.

Table 1. The GC-MS analysis of the crude ethyl acetate obtained from wet mycelial biomass produced using ascospores of T. nivea.

\begin{tabular}{|c|c|c|c|c|c|}
\hline Compound Name & Chemical Formula & $\begin{array}{l}\text { Molecular Weight } \\
\text { (g/mol) }\end{array}$ & RT (min) & Quality & Area $\%$ \\
\hline Hexanal & $\mathrm{C}_{6} \mathrm{H}_{12} \mathrm{O}$ & 100.16 & 4.346 & 47 & 1 \\
\hline 1H-Indene, 1-ethylideneoctahydro-7a-methyl-, cis- & $\mathrm{C}_{12} \mathrm{H}_{20}$ & 164.29 & 5.072 & 64 & 5.4 \\
\hline 9-Nitroanthracene & $\mathrm{C}_{14} \mathrm{H}_{9} \mathrm{NO}_{2}$ & 223.23 & 7.756 & 9 & 0.8 \\
\hline 3-(4-nitrophenyl)-1-phenylprop-2-en-1-one & $\mathrm{C}_{15} \mathrm{H}_{11} \mathrm{NO}_{3}$ & 253.25 & 7.96 & 47 & 1.9 \\
\hline 8-Methyloctahydrocoumarin & $\mathrm{C}_{10} \mathrm{H}_{16} \mathrm{O}_{2}$ & 168.23 & 9.652 & 27 & 0.8 \\
\hline Dodecane & $\mathrm{C}_{12} \mathrm{H}_{26}$ & 170.33 & 10.212 & 49 & 2.7 \\
\hline $\begin{array}{l}\text { (1E)-1-(4-Hydroxyphenyl)ethenone ((2Z)-3-methyl- } \\
\text { 1,3-benzothiazol-2(3H)xylidine)hydrazone }\end{array}$ & $\mathrm{C}_{16} \mathrm{H}_{15} \mathrm{~N}_{3} \mathrm{OS}$ & 297.4 & 13.081 & 22 & 1 \\
\hline 5,9-Undecadien-1-yne, 6,10-dimethyl- & $\mathrm{C}_{13} \mathrm{H}_{20}$ & 176.3 & 13.648 & 35 & 1 \\
\hline 2,4-Di-tert-butylphenol & $\mathrm{C}_{14} \mathrm{H}_{22} \mathrm{O}$ & 206.32 & 15.035 & 76 & 1.4 \\
\hline beta-Cadinene & $\mathrm{C}_{15} \mathrm{H}_{24}$ & 204.35 & 15.162 & 46 & 0.9 \\
\hline $\begin{array}{l}\text { 4-Hydroxyphenylacetic acid, ethyl ester, } \\
\text { tert-butyl-dimethyl-silyl }\end{array}$ & $\mathrm{C}_{16} \mathrm{H}_{26} \mathrm{O}_{3} \mathrm{Si}$ & 294.46 & 15.569 & 38 & 2.5 \\
\hline 1-Octadecanesulphonyl chloride & $\mathrm{C}_{18} \mathrm{H}_{37} \mathrm{ClO}_{2} \mathrm{~S}$ & 353 & 16.052 & 52 & 1.5 \\
\hline Heptadecane & $\mathrm{C}_{17} \mathrm{H}_{36}$ & 240.5 & 17.331 & 90 & 1.9 \\
\hline Nafoxidine & $\mathrm{C}_{29} \mathrm{H}_{31} \mathrm{NO}_{2}$ & 425.6 & 17.662 & 27 & 2.3 \\
\hline cis-7, cis-11-Hexadecadien-1-yl acetate & $\mathrm{C}_{18} \mathrm{H}_{32} \mathrm{O}_{2}$ & 280.4 & 18.502 & 55 & 1.9 \\
\hline
\end{tabular}


Table 1. Cont.

\begin{tabular}{|c|c|c|c|c|c|}
\hline Compound Name & Chemical Formula & $\begin{array}{l}\text { Molecular Weight } \\
\text { (g/mol) }\end{array}$ & RT (min) & Quality & Area $\%$ \\
\hline 7-Hexadecenal, (Z)- & $\mathrm{C}_{16} \mathrm{H}_{30} \mathrm{O}$ & 238.41 & 18.61 & 53 & 1 \\
\hline Oleic Acid & $\mathrm{C}_{18} \mathrm{H}_{34} \mathrm{O}_{2}$ & 282.5 & 19.367 & 25 & 1.1 \\
\hline 1-Eicosene & $\mathrm{C}_{20} \mathrm{H}_{40}$ & 280.5 & 19.59 & 83 & 1.6 \\
\hline Methyl palmitate & $\mathrm{C}_{17} \mathrm{H}_{34} \mathrm{O}_{2}$ & 270.5 & 19.889 & 98 & 11.5 \\
\hline Z,E-7,11-Hexadecadien-1-yl acetate & $\mathrm{C}_{18} \mathrm{H}_{32} \mathrm{O}_{2}$ & 280.4 & 19.952 & 72 & 1 \\
\hline Tetra-decanoic acid & $\mathrm{C}_{14} \mathrm{H}_{28} \mathrm{O}_{2}$ & 228.37 & 20.379 & 74 & 17.2 \\
\hline Phenol, o-(2-butenylsulfinyl)- & $\mathrm{C}_{10} \mathrm{H}_{12} \mathrm{O}_{2} \mathrm{~S}$ & 196.27 & 20.614 & 35 & 6 \\
\hline $\begin{array}{l}\text { Pyrimidin-4-one, } \\
\text { hexahydro-3-hydroxy-2-(4-nitrophenyl)- }\end{array}$ & $\mathrm{C}_{10} \mathrm{H}_{11} \mathrm{~N}_{3} \mathrm{O}_{4}$ & 237.21 & 20.996 & 50 & 1.9 \\
\hline Methyl linolelaidate & $\mathrm{C}_{19} \mathrm{H}_{34} \mathrm{O}_{2}$ & 294.5 & 21.575 & 99 & 9.5 \\
\hline Methyl oleate & $\mathrm{C} 19 \mathrm{H} 36 \mathrm{O} 2$ & 296.5 & 21.625 & 99 & 10.9 \\
\hline Methyl stearate & $\mathrm{C}_{19} \mathrm{H}_{38} \mathrm{O}_{2}$ & 298.5 & 21.855 & 89 & 3 \\
\hline 9,12-Octadecadienoic acid (Z,Z)- & $\mathrm{C}_{18} \mathrm{H}_{32} \mathrm{O}_{2}$ & 280.4 & 22.109 & 99 & 3.5 \\
\hline Z,Z-11,13-Hexadecadien-1-ol & $\mathrm{C}_{16} \mathrm{H}_{30} \mathrm{O}$ & 238.41 & 22.408 & 56 & 2.2 \\
\hline 7-Penta-decyne & $\mathrm{C}_{15} \mathrm{H}_{28}$ & 208.38 & 22.713 & 92 & 1.5 \\
\hline $\begin{array}{l}\text { Pyrimidin-4-one, } \\
\text { hexahydro-3-hydroxy-2-(4-nitrophenyl)- }\end{array}$ & $\mathrm{C}_{10} \mathrm{H}_{11} \mathrm{~N}_{3} \mathrm{O}_{4}$ & 237.21 & 23.7 & 27 & 1.2 \\
\hline
\end{tabular}

Table 2. The GC-MS analysis of the crude ethyl acetate obtained from mycelia-free medium that used to cultivation of ascospores of T. nivea.

\begin{tabular}{|c|c|c|c|c|c|}
\hline Compound Name & Chemical Formula & $\begin{array}{l}\text { Molecular Weight } \\
\text { (g/mol) }\end{array}$ & RT (min) & Quality & Area $\%$ \\
\hline 2,4-Di-tert-butylphenol & $\mathrm{C}_{14} \mathrm{H}_{22} \mathrm{O}$ & 206.32 & 15.009 & 97 & 59.3 \\
\hline 4-Amino-7-diethylamino-chromen-2-one & $\mathrm{C}_{13} \mathrm{H}_{16} \mathrm{~N}_{2} \mathrm{O}_{2}$ & 232.28 & 16.568 & 64 & 0.5 \\
\hline Heptadecane & $\mathrm{C}_{17} \mathrm{H}_{36}$ & 240.5 & 17.312 & 90 & 0.6 \\
\hline Methyl 8-methyl-decanoate & $\mathrm{C}_{12} \mathrm{H}_{24} \mathrm{O}_{2}$ & 200.32 & 17.649 & 42 & 0.7 \\
\hline 3,5-di-tert-Butyl-4-hydroxybenzaldehyde & $\mathrm{C}_{15} \mathrm{H}_{22} \mathrm{O}_{2}$ & 234.33 & 18.292 & 95 & 0.4 \\
\hline 1-Octadecene & $\mathrm{C}_{18} \mathrm{H}_{36}$ & 252.5 & 18.425 & 98 & 1.4 \\
\hline Octadecane & $\mathrm{C}_{18} \mathrm{H}_{38}$ & 245.5 & 18.495 & 86 & 0.4 \\
\hline 2-Ethyl-1,3,4-trimethyl-3-pyrazolin-5-one & $\mathrm{C}_{8} \mathrm{H}_{14} \mathrm{~N}_{2} \mathrm{O}$ & 154.21 & 18.973 & 46 & 1 \\
\hline 9-Methylnonadecane & $\mathrm{C}_{20} \mathrm{H}_{42}$ & 282.5 & 19.59 & 76 & 0.5 \\
\hline METHYL PALMITATE & $\mathrm{C}_{17} \mathrm{H}_{34} \mathrm{O}_{2}$ & 270.5 & 19.882 & 95 & 0.4 \\
\hline $\begin{array}{l}\text { 2,5-Cyclohexadien-1-one, } \\
\text { 2,6-bis(1,1-dimethylethyl)-4-ethylidene- }\end{array}$ & $\mathrm{C}_{16} \mathrm{H}_{24} \mathrm{O}$ & 232.36 & 19.965 & 78 & 4.4 \\
\hline Benzene, 1-methoxy-2-(methylthio)- & $\mathrm{C}_{8} \mathrm{H}_{10} \mathrm{OS}$ & 154.229 & 20.175 & 43 & 1.2 \\
\hline BUTYL ISOBUTYL PHTHALATE & $\mathrm{C}_{16} \mathrm{H}_{22} \mathrm{O}_{4}$ & 278.34 & 20.353 & 80 & 1.4 \\
\hline 1-Eicosene & $\mathrm{C}_{20} \mathrm{H}_{40}$ & 280.5 & 20.557 & 95 & 0.7 \\
\hline 4-(2,2-dimethylpropionylamino)benzoic acid & $\mathrm{C}_{12} \mathrm{H}_{15} \mathrm{NO}_{3}$ & 221.5 & 20.601 & 15 & 0.9 \\
\hline 4-(2-phenylquinazolin-4-yl)morpholine & $\mathrm{C}_{18} \mathrm{H}_{17} \mathrm{~N}_{3} \mathrm{O}$ & 291.3 & 20.773 & 93 & 1.5 \\
\hline Chlorpropham & $\mathrm{C}_{10} \mathrm{H}_{12} \mathrm{C}_{1} \mathrm{NO}_{2}$ & 213.66 & 21.365 & 52 & 1.5 \\
\hline Z-8-Hexadecene & $\mathrm{C}_{16} \mathrm{H}_{32}$ & 242.42 & 21.479 & 99 & 5.7 \\
\hline Cyclopentadecanone, 2-hydroxy- & $\mathrm{C}_{15} \mathrm{H}_{28} \mathrm{O}$ & 240.38 & 21.625 & 93 & 0.5 \\
\hline 3,4-Octadiene, 7-methyl- & $\mathrm{C}_{9} \mathrm{H}_{16}$ & 142.22 & 22.306 & 70 & 0.6 \\
\hline Octa-decanamide & $\mathrm{C}_{18} \mathrm{H}_{37} \mathrm{NO}$ & 283.5 & 22.44 & 78 & 0.8 \\
\hline D-Homo-androstane (5.alpha.,13.alpha.)- & $\mathrm{C} 2 \mathrm{OH}_{34}$ & 274.5 & 23.241 & 84 & 0.3 \\
\hline 2-(Diphenyl-phosphoryl)-4-nitrophenol & $\mathrm{C}_{18} \mathrm{H}_{14} \mathrm{NO}_{4} \mathrm{P}$ & 339.3 & 23.973 & 90 & 1.2 \\
\hline 9-Octadecenamide, $(\mathrm{Z})$ - & $\mathrm{C}_{18} \mathrm{H}_{35} \mathrm{NO}$ & 281.5 & 24.107 & 97 & 12.6 \\
\hline Stigmasta-4,6,22-trien-3.beta.-ol & $\mathrm{C}_{29} \mathrm{H}_{46} \mathrm{O}$ & 410.7 & 25.265 & 93 & 0.4 \\
\hline $\begin{array}{l}\text { 2-Pyridinecarbohydrazonamide, } \\
\mathrm{N}^{\prime} \text {-[(2,4-dimethoxyphenyl)methylidene]- }\end{array}$ & $\mathrm{C}_{15} \mathrm{H}_{16} \mathrm{~N}_{4} \mathrm{O}_{2}$ & 284.31 & 25.468 & 95 & 0.7 \\
\hline $\begin{array}{l}\text { Androsta[17-16-b]furan-5'-imine, } \\
\text { 4'-methylene-3-methoxy-N-cyclohexyl- }\end{array}$ & $\mathrm{C}_{29} \mathrm{H}_{45} \mathrm{NO}_{2}$ & 439.7 & 26.238 & 42 & 0.5 \\
\hline
\end{tabular}


Table 3. The GC-MS analysis of the crude methanol extract obtained from wet mycelial biomass produced using ascospores of T. nivea.

\begin{tabular}{|c|c|c|c|c|c|}
\hline Compound Name & $\begin{array}{l}\text { Chemical } \\
\text { Formula }\end{array}$ & $\begin{array}{c}\text { Molecular } \\
\text { Weight (g/mol) }\end{array}$ & RT (min) & Quality & Area $\%$ \\
\hline Dodecane & $\mathrm{C}_{12} \mathrm{H}_{26}$ & 170.33 & 10.231 & 53 & 4.4 \\
\hline 7-Pentadecyne & $\mathrm{C}_{15} \mathrm{H}_{28}$ & 208.33 & 19.685 & 90 & 1.4 \\
\hline Methyl palmitate & $\mathrm{C}_{17} \mathrm{H}_{34} \mathrm{O}_{2}$ & 270.5 & 19.889 & 98 & 16.9 \\
\hline Palmitic acid & $\mathrm{C}_{16} \mathrm{H}_{32} \mathrm{O}_{2}$ & 256.42 & 20.353 & 90 & 10.4 \\
\hline Methyl linolelaidate & $\mathrm{C}_{19} \mathrm{H}_{34} \mathrm{O}_{2}$ & 294.5 & 21.575 & 99 & 18 \\
\hline Methyl oleate & $\mathrm{C}_{19} \mathrm{H}_{36} \mathrm{O}_{2}$ & 296.5 & 21.626 & 99 & 30 \\
\hline Methyl isostearate & $\mathrm{C}_{19} \mathrm{H}_{38} \mathrm{O}_{2}$ & 298.5 & 21.848 & 95 & 3.2 \\
\hline $\begin{array}{l}\text { 2,5-Dihydroxy-2-(4-methyl- } \\
\text { pent-3-enyl)-2,3- } \\
\text { dihydrobenzofuran-3,4- } \\
\text { dicarboxylic acid, 3-ethyl ester } \\
\text { 4-methyl ester }\end{array}$ & $\mathrm{C}_{19} \mathrm{H}_{24} \mathrm{O}_{7}$ & 364.4 & 27.491 & 27 & 5.2 \\
\hline $\begin{array}{l}\text { 1-[(Z)-3-Hydroxy-3-phenyl-1- } \\
\text { triazenyl]anthra-9,10-quinone }\end{array}$ & $\mathrm{C}_{20} \mathrm{H}_{13} \mathrm{~N}_{3} \mathrm{O}_{3}$ & 343.3 & 28.707 & 59 & 10.6 \\
\hline
\end{tabular}

Table 4. The GC-MS analysis of the crude methanol extract obtained from mycelia-free medium that used to cultivation of ascospores of T. nivea.

\begin{tabular}{|c|c|c|c|c|c|}
\hline Compound Name & $\begin{array}{l}\text { Chemical } \\
\text { Formula }\end{array}$ & $\begin{array}{c}\text { Molecular } \\
\text { Weight (g/mol) }\end{array}$ & RT (min) & Quality & Area $\%$ \\
\hline \multirow{3}{*}{$\begin{array}{c}\text { 1-Piperidineethanol } \\
\text { 5-Methyl furfural } \\
\text { 2,4-Dihydroxy-2,5-dimethyl- } \\
\text { 3(2H)-furanone }\end{array}$} & $\mathrm{C}_{7} \mathrm{H}_{15} \mathrm{NO}$ & 129.2 & 6.331 & 72 & 1.6 \\
\hline & $\mathrm{C}_{6} \mathrm{H}_{6} \mathrm{O} 2$ & 110.11 & 6.745 & 90 & 2.3 \\
\hline & $\mathrm{C}_{6} \mathrm{H}_{8} \mathrm{O}_{4}$ & 144.12 & 7.025 & 52 & 0.8 \\
\hline $\begin{array}{l}\text { 1,3-Dioxane-2-propanol, } \\
\text { 2-methyl- }\end{array}$ & $\mathrm{C}_{8} \mathrm{H}_{16} \mathrm{O}_{3}$ & 160.21 & 7.4 & 22 & 0.6 \\
\hline \multirow{2}{*}{$\begin{array}{l}\text { 2-Hydroxy-gamma- } \\
\text { butyrolactone } \\
\text { trans-1,2,5,5-Tetramethyl-3,7,9- } \\
\text { trioxabicyclo }(4,2,1) \text { nonane }\end{array}$} & $\mathrm{C}_{4} \mathrm{H}_{6} \mathrm{O}_{3}$ & 102.09 & 7.572 & 53 & 3.2 \\
\hline & $\mathrm{C}_{10} \mathrm{H}_{18} \mathrm{O}_{3}$ & 186.25 & 8.03 & 43 & 0.4 \\
\hline \multirow{3}{*}{$\begin{array}{l}\text { 1,3-Dimethyl-2-imidazolidinone } \\
\text { 2-Methyl-5-(methylthio)furan } \\
\text { 2-Methoxy-6-methylpyrazine }\end{array}$} & $\mathrm{C}_{5} \mathrm{H}_{10} \mathrm{~N}_{2} \mathrm{O}$ & 114.15 & 8.253 & 47 & 0.8 \\
\hline & $\mathrm{C}_{6} \mathrm{H}_{8} \mathrm{OS}$ & 128.19 & 8.431 & 59 & 2.1 \\
\hline & $\mathrm{C}_{6} \mathrm{H}_{8} \mathrm{~N}_{2} \mathrm{O}$ & 124.14 & 8.59 & 72 & 0.9 \\
\hline $\begin{array}{l}\text { 2-Methoxy-6-methylpyrazine } \\
\text { Methyl 2-furoate }\end{array}$ & $\mathrm{C}_{6} \mathrm{H}_{6} \mathrm{O}_{3}$ & 126.11 & 8.685 & 30 & 1.4 \\
\hline Glutaraldehyde & $\mathrm{C}_{5} \mathrm{H}_{8} \mathrm{O}_{2}$ & 100.12 & 8.914 & 50 & 3.6 \\
\hline \multirow{2}{*}{$\begin{array}{l}\text { Maltol } \\
\text { 4H-Pyran-4-one, 2,3-dihydro-3,5- } \\
\text { dihydroxy-6-methyl- }\end{array}$} & $\mathrm{C}_{6} \mathrm{H}_{6} \mathrm{O}_{3}$ & 126.11 & 9.137 & 83 & 0.6 \\
\hline & $\mathrm{C}_{6} \mathrm{H}_{8} \mathrm{O}_{4}$ & 144.12 & 9.722 & 62 & 15.6 \\
\hline \multirow{2}{*}{$\begin{array}{l}\text { 5-Hydroxymaltol } \\
\text { 5-hydroxymethe high-furfural }\end{array}$} & $\mathrm{C}_{6} \mathrm{H}_{6} \mathrm{O}_{4}$ & 142.11 & 10.346 & 91 & 0.6 \\
\hline & $\mathrm{C}_{6} \mathrm{H}_{6} \mathrm{O}_{3}$ & 126.11 & 11.109 & 91 & 38.9 \\
\hline $\begin{array}{l}\text { 5-Isopropenyl-2-methylpyridine } \\
\text { 3-Furanacetic acid }\end{array}$ & $\mathrm{C}_{9} \mathrm{H}_{11} \mathrm{~N}$ & 133.19 & 13.037 & 46 & 1.7 \\
\hline \multirow{2}{*}{$\begin{array}{l}\text { 3-Furanacetic acid, } \\
\text { 4-hexyl-2,5-dihydro-2,5-dioxo- } \\
\text { Nonanoic acid }\end{array}$} & $\mathrm{C}_{12} \mathrm{H}_{16} \mathrm{O}_{5}$ & 240.25 & 14.589 & 74 & 21.6 \\
\hline & $\mathrm{C}_{9} \mathrm{H}_{18} \mathrm{O}_{2}$ & 158.24 & 15.308 & 55 & 1.6 \\
\hline \multirow{2}{*}{$\begin{array}{l}\text { 2,3-Dimethyl-8-oxo-non-2-enal } \\
\text { Dodemorph }\end{array}$} & $\mathrm{C} 11 \mathrm{H}_{18} \mathrm{O}_{2}$ & 182.26 & 17.999 & 27 & 0.9 \\
\hline & $\mathrm{C}_{18} \mathrm{H}_{35} \mathrm{NO}$ & 281.5 & 20.328 & 25 & 0.8 \\
\hline
\end{tabular}


Table 5. The GC-MS analysis of the crude hexane extract obtained from wet mycelial biomass produced using ascospores of T. nivea.

\begin{tabular}{|c|c|c|c|c|c|}
\hline Compound Name & $\begin{array}{l}\text { Chemical } \\
\text { Formula }\end{array}$ & $\begin{array}{c}\text { Molecular } \\
\text { Weight (g/mol) }\end{array}$ & RT (min) & Quality & Area $\%$ \\
\hline $\begin{array}{l}\text { 1,5-Dimethyl-4- } \\
\text { allylaminocytosine }\end{array}$ & $\mathrm{C}_{9} \mathrm{H}_{13} \mathrm{~N}_{3} \mathrm{O}$ & 179.22 & 5.065 & 38 & 2.3 \\
\hline $\begin{array}{l}\text { 3-(4-nitrophenyl)-1- } \\
\text { phenylprop-2-en-1-one }\end{array}$ & $\mathrm{C}_{15} \mathrm{H}_{11} \mathrm{NO}_{3}$ & 253.25 & 7.954 & 47 & 0.8 \\
\hline $\begin{array}{l}\text { 4-Phenoxy-2-quinolinol } \\
\text { 2,5-Cyclohexadien-1-one }\end{array}$ & $\mathrm{C}_{15} \mathrm{H}_{11} \mathrm{NO}_{2}$ & 237.25 & 15.575 & 25 & 1.4 \\
\hline $\begin{array}{l}\text { 2,6-bis(1,1-dimethylethyl)-4- } \\
\text { ethylidene- }\end{array}$ & $\mathrm{C}_{16} \mathrm{H}_{24} \mathrm{O}$ & 232.36 & 16.568 & 62 & 0.7 \\
\hline Tritriacontane & $\mathrm{C}_{43} \mathrm{H}_{88}$ & 605.2 & 17.331 & 58 & 1.1 \\
\hline $\begin{array}{c}\text { Carbonic acid, octadecyl } \\
\text { 2,2,2-trichloroethyl ester } \\
\text { Phthalic acid }\end{array}$ & $\mathrm{C}_{21} \mathrm{H}_{39} \mathrm{C}_{13} \mathrm{O}_{3}$ & 445.9 & 19.214 & 60 & 1.2 \\
\hline $\begin{array}{l}\text { 3-(2-methoxyethyl)heptyl } \\
\text { propyl ester }\end{array}$ & $\mathrm{C}_{21} \mathrm{H}_{32} \mathrm{O}_{5}$ & 364.5 & 19.367 & 59 & 0.7 \\
\hline $\begin{array}{l}\text { Penta-decyl } \\
\text { heptafluorobutyrate }\end{array}$ & $\mathrm{C}_{19} \mathrm{H}_{31} \mathrm{~F}_{7} \mathrm{O}_{2}$ & 424.4 & 19.526 & 93 & 0.9 \\
\hline $\begin{array}{l}\text { METHYL PALMITATE } \\
\text { 7,9-Di-tert-butyl-1- }\end{array}$ & $\mathrm{C}_{17} \mathrm{H}_{34} \mathrm{O}_{2}$ & 270.5 & 19.882 & 97 & 4.3 \\
\hline $\begin{array}{l}\text { oxaspiro(4,5)deca-6,9-diene-2,8- } \\
\text { dione }\end{array}$ & $\mathrm{C}_{17} \mathrm{H}_{24} \mathrm{O}_{3}$ & 276.4 & 19.946 & 97 & 5.6 \\
\hline \multirow{2}{*}{$\begin{array}{l}\text { Cyclo-hexadecane, 1,2-diethyl- } \\
\text { 5-Amino-1,3-dihydro-2H- } \\
\text { benzimidazol-2-one }\end{array}$} & $\mathrm{C}_{20} \mathrm{H}_{40}$ & 280.5 & 20.181 & 70 & 0.7 \\
\hline & $\mathrm{C}_{7} \mathrm{H}_{7} \mathrm{~N}_{3} \mathrm{O}$ & 149.15 & 20.359 & 46 & 5.9 \\
\hline \multirow{4}{*}{$\begin{array}{l}\text { 3-Buten-2-one, 4-(dimethyl- } \\
\text { amino)-3-(methylamino)- } \\
\text { 11-Dodecen-1-ol trifluoroacetate } \\
\text { Pyrimidin-4-one, hexahydro-3- } \\
\text { hydroxy-2-(4-nitrophenyl)- } \\
\text { 2-Methyl-7-nonadecene }\end{array}$} & $\mathrm{C}_{7} \mathrm{H}_{14} \mathrm{~N}_{2} \mathrm{O}$ & 142.2 & 20.595 & 46 & 16.3 \\
\hline & $\mathrm{C}_{14} \mathrm{H}_{23} \mathrm{~F}_{3} \mathrm{O}_{2}$ & 280.33 & 20.868 & 90 & 0.8 \\
\hline & $\mathrm{C}_{10} \mathrm{H}_{11} \mathrm{~N}_{3} \mathrm{O}_{4}$ & 237.21 & 20.996 & 44 & 0.6 \\
\hline & $\mathrm{C}_{20} \mathrm{H}_{40}$ & 280.5 & 21.307 & 86 & 1 \\
\hline E-15-Heptadecenal & $\mathrm{C}_{17} \mathrm{H}_{32} \mathrm{O}$ & 252.4 & 21.473 & 97 & 4.5 \\
\hline Methyl linoleate & $\mathrm{C}_{19} \mathrm{H}_{34} \mathrm{O}_{2}$ & 294.5 & 21.575 & 99 & 2 \\
\hline Methyl oleate & $\mathrm{C}_{19} \mathrm{H}_{36} \mathrm{O}_{2}$ & 296.5 & 21.626 & 99 & 7.5 \\
\hline Methyl stearate & $\mathrm{C}_{19} \mathrm{H}_{38} \mathrm{O}_{2}$ & 298.5 & 21.848 & 86 & 1.6 \\
\hline Linolic acid & $\mathrm{C}_{18} \mathrm{H}_{32} \mathrm{O}_{2}$ & 280.4 & 22.128 & 70 & 1.2 \\
\hline Allyl-cyclo-hexane & $\mathrm{C}_{9} \mathrm{H}_{16}$ & 124.22 & 22.332 & 62 & 1.3 \\
\hline $\begin{array}{l}\text { Pyridine-3-carboxamide, oxime, } \\
\text { N-(2-trifluoromethylphenyl)- }\end{array}$ & $\mathrm{C}_{13} \mathrm{H}_{10} \mathrm{~F}_{3} \mathrm{~N}_{3} \mathrm{O}$ & 281.23 & 22.402 & 92 & 0.7 \\
\hline 3-Deoxy-17.beta.-estradiol & $\mathrm{C}_{18} \mathrm{H}_{24} \mathrm{O}$ & 256.4 & 22.586 & 49 & 0.8 \\
\hline $\begin{array}{c}\text { Cyclohexene, } \\
\text { 4-(4-ethylcyclohexyl)-1-pentyl- }\end{array}$ & $\mathrm{C}_{19} \mathrm{H}_{34}$ & 262.5 & 22.707 & 56 & 1.4 \\
\hline $\begin{array}{l}\text { p-Menth-8(10)-en-9-ol } \\
\text { Cyclohexane, }\end{array}$ & $\mathrm{C}_{10} \mathrm{H}_{18} \mathrm{O}$ & 154.25 & 22.796 & 53 & 0.6 \\
\hline $\begin{array}{l}\text { 1-(1,5-dimethylhexyl)-4-(4- } \\
\text { methylpentyl)- }\end{array}$ & $\mathrm{C}_{20} \mathrm{H}_{40}$ & 280.5 & 23.178 & 92 & 1.1 \\
\hline 9-Octadecenamide, (Z)- & $\mathrm{C}_{18} \mathrm{H}_{35} \mathrm{NO}$ & 281.5 & 24.145 & 93 & 30.7 \\
\hline $\begin{array}{l}\text { Pyridine-3-carboxamide, oxime, } \\
\text { N-(2-trifluoromethylphenyl)- }\end{array}$ & $\mathrm{C}_{13} \mathrm{H}_{10} \mathrm{~F}_{3} \mathrm{~N}_{3} \mathrm{O}$ & 281.23 & 24.883 & 95 & 1 \\
\hline $\begin{array}{l}\text { 1,2-Benzenedicarboxylic acid, } \\
\text { mono(2-ethylhexyl) ester }\end{array}$ & $\mathrm{C}_{16} \mathrm{H}_{22} \mathrm{O}_{4}$ & 278.34 & 25.468 & 52 & 1.7 \\
\hline
\end{tabular}


Table 6. GC-MS analysis of the crude hexane extract obtained from mycelia-free medium used in cultivation of ascospores of T. nivea.

\begin{tabular}{|c|c|c|c|c|c|}
\hline Compound Name & $\begin{array}{l}\text { Chemical } \\
\text { Formula }\end{array}$ & $\begin{array}{c}\text { Molecular } \\
\text { Weight (g/mol) }\end{array}$ & RT (min) & Quality & Area $\%$ \\
\hline $\begin{array}{l}\text { 2-(2-Methoxy-5-methyl-phenyl)- } \\
\text { propionaldehyde }\end{array}$ & $\mathrm{C}_{11} \mathrm{H}_{14} \mathrm{O}_{2}$ & 178.23 & 5.091 & 35 & 0.9 \\
\hline Viridicatol & $\mathrm{C}_{15} \mathrm{H}_{11} \mathrm{NO}_{3}$ & 253.25 & 7.96 & 38 & 0.7 \\
\hline Heptacosane & $\mathrm{C}_{27} \mathrm{H}_{56}$ & 380.7 & 10.238 & 58 & 1 \\
\hline $\begin{array}{l}\text { Caryophyllene } \\
\text { Naphthalene, }\end{array}$ & $\mathrm{C}_{15} \mathrm{H}_{24}$ & 204.35 & 13.648 & 58 & 0.7 \\
\hline $\begin{array}{c}\text { 1,2,3,5,6,8a-hexahydro-4,7- } \\
\text { dimethyl-1-(1-methylethyl)-, } \\
\text { (1S-cis)- }\end{array}$ & $\mathrm{C}_{15} \mathrm{H}_{24}$ & 204.35 & 15.162 & 83 & 0.6 \\
\hline Tetratriacontane & $\mathrm{C}_{34} \mathrm{H}_{70}$ & 478.9 & 17.325 & 72 & 0.7 \\
\hline alpha.-Bisabol oxide B & $\mathrm{C}_{15} \mathrm{H}_{26} \mathrm{O}_{2}$ & 238.37 & 17.662 & 35 & 2.5 \\
\hline $\begin{array}{l}\text { 5-Dimethylamino-furan-2- } \\
\text { carbaldehyde }\end{array}$ & $\mathrm{C}_{7} \mathrm{H}_{9} \mathrm{NO}_{2}$ & 139.15 & 19.202 & 43 & 4.7 \\
\hline $\begin{array}{l}\text { Phthalic acid, isobutyl } \\
\text { non-5-yn-3-yl ester }\end{array}$ & $\mathrm{C}_{21} \mathrm{H}_{28} \mathrm{O}_{4}$ & 344.4 & 19.367 & 72 & 1.8 \\
\hline $\begin{array}{l}\text { Methyl 14-methylpentadecanoate } \\
\text { 7,9-Di-tert-butyl-1- }\end{array}$ & $\mathrm{C}_{17} \mathrm{H}_{34} \mathrm{O}_{2}$ & 270.5 & 19.882 & 97 & 3 \\
\hline $\begin{array}{l}\text { oxaspiro(4,5)deca-6,9-diene- } \\
\text { 2,8-dione }\end{array}$ & $\mathrm{C}_{17} \mathrm{H}_{24} \mathrm{O}_{3}$ & 276.4 & 19.946 & 93 & 2 \\
\hline 9,12-Octadecadienoic acid (Z,Z)- & $\mathrm{C}_{18} \mathrm{H}_{32} \mathrm{O}_{2}$ & 280.4 & 20.124 & 44 & 1.1 \\
\hline Dibutyl phthalate & $\mathrm{C}_{16} \mathrm{H}_{22} \mathrm{O}_{4}$ & 278.34 & 20.366 & 81 & 13.1 \\
\hline p-Menth-8(10)-en-9-ol & $\mathrm{C}_{10} \mathrm{H}_{18} \mathrm{O}$ & 154.25 & 20.875 & 90 & 0.8 \\
\hline 3-Eicosene, (E)- & $\mathrm{C}_{20} \mathrm{H}_{40}$ & 280.5 & 21.307 & 89 & 0.7 \\
\hline n-Nonadecanol-1 & $\mathrm{C}_{19} \mathrm{H}_{40} \mathrm{O}$ & 284.5 & 21.467 & 95 & 2.8 \\
\hline Methyl vaccenate & $\mathrm{C}_{19} \mathrm{H}_{36} \mathrm{O}_{2}$ & 296.5 & 21.626 & 99 & 3.2 \\
\hline $\begin{array}{c}\text { Methyl } \\
\text { 16-methyl-heptadecanoate }\end{array}$ & $\mathrm{C}_{19} \mathrm{H}_{38} \mathrm{O}_{2}$ & 298.5 & 21.848 & 96 & 2.1 \\
\hline (1-Propylnonyl)cyclohexane & $\mathrm{C}_{18} \mathrm{H}_{36}$ & 252.5 & 22.332 & 64 & 0.9 \\
\hline 1-Docosene & $\mathrm{C}_{22} \mathrm{H}_{44}$ & 308.6 & 22.44 & 98 & 2.8 \\
\hline $\begin{array}{l}\text { Cyclo-pentadecane } \\
\text { Cyclohexane, }\end{array}$ & $\mathrm{C}_{15} \mathrm{H}_{30}$ & 210.4 & 22.586 & 90 & 1.3 \\
\hline $\begin{array}{l}\text { 1-(1,5-dimethylhexyl)-4-(4- } \\
\text { methylpentyl)- }\end{array}$ & $\mathrm{C}_{20} \mathrm{H}_{40}$ & 280.5 & 23.184 & 94 & 0.7 \\
\hline $\begin{array}{l}\text { Bicyclo[2.1.1]hexane-1-carboxylic } \\
\text { acid, 5,5-dimethyl- }\end{array}$ & $\mathrm{C}_{9} \mathrm{H}_{14} \mathrm{O}_{2}$ & 154.21 & 23.413 & 87 & 0.9 \\
\hline Bis(2-ethylhexyl) adipate & $\mathrm{C}_{22} \mathrm{H}_{42} \mathrm{O}_{4}$ & 370.6 & 24.234 & 95 & 12.1 \\
\hline Dicyclo-hexyl phthalate & $\mathrm{C}_{20} \mathrm{H}_{26} \mathrm{O}_{4}$ & 330.4 & 25.366 & 87 & 9.9 \\
\hline Diiso-octyl phthalate & $\mathrm{C}_{24} \mathrm{H}_{38} \mathrm{O}_{4}$ & 390.6 & 25.468 & 86 & 15.4 \\
\hline $\begin{array}{l}\text { Pyridine-3-carboxamide, oxime, } \\
\text { N-(2-trifluoromethylphenyl)- }\end{array}$ & $\mathrm{C}_{13} \mathrm{H}_{10} \mathrm{~F}_{3} \mathrm{~N}_{3} \mathrm{O}$ & 281.23 & 25.748 & 93 & 2.2 \\
\hline Isophthalic acid, di(4-octyl) ester & $\mathrm{C}_{24} \mathrm{H}_{38} \mathrm{O}_{4}$ & 390.6 & 26.938 & 68 & 11.3 \\
\hline
\end{tabular}

\subsection{Biological Activity of Crude Alcoholic Extracts}

The data from the disk diffusion test showed that all the extracts had biological activity against all the tested microorganisms. The inhibition zones resulting from the activity of the extracts ranged from $8 \mathrm{~mm}$ to about $13 \mathrm{~mm}$. The findings showed that crude methanol hexane extracts of the mycelia-free broth had the highest biological activity against tested microbes among all extracts investigated in this work (Table 7). 
Table 7. The biological activity of the crude extracts obtained from the biomass of T. nevia and mycelia-free medium $(\mathrm{N}=3)$.

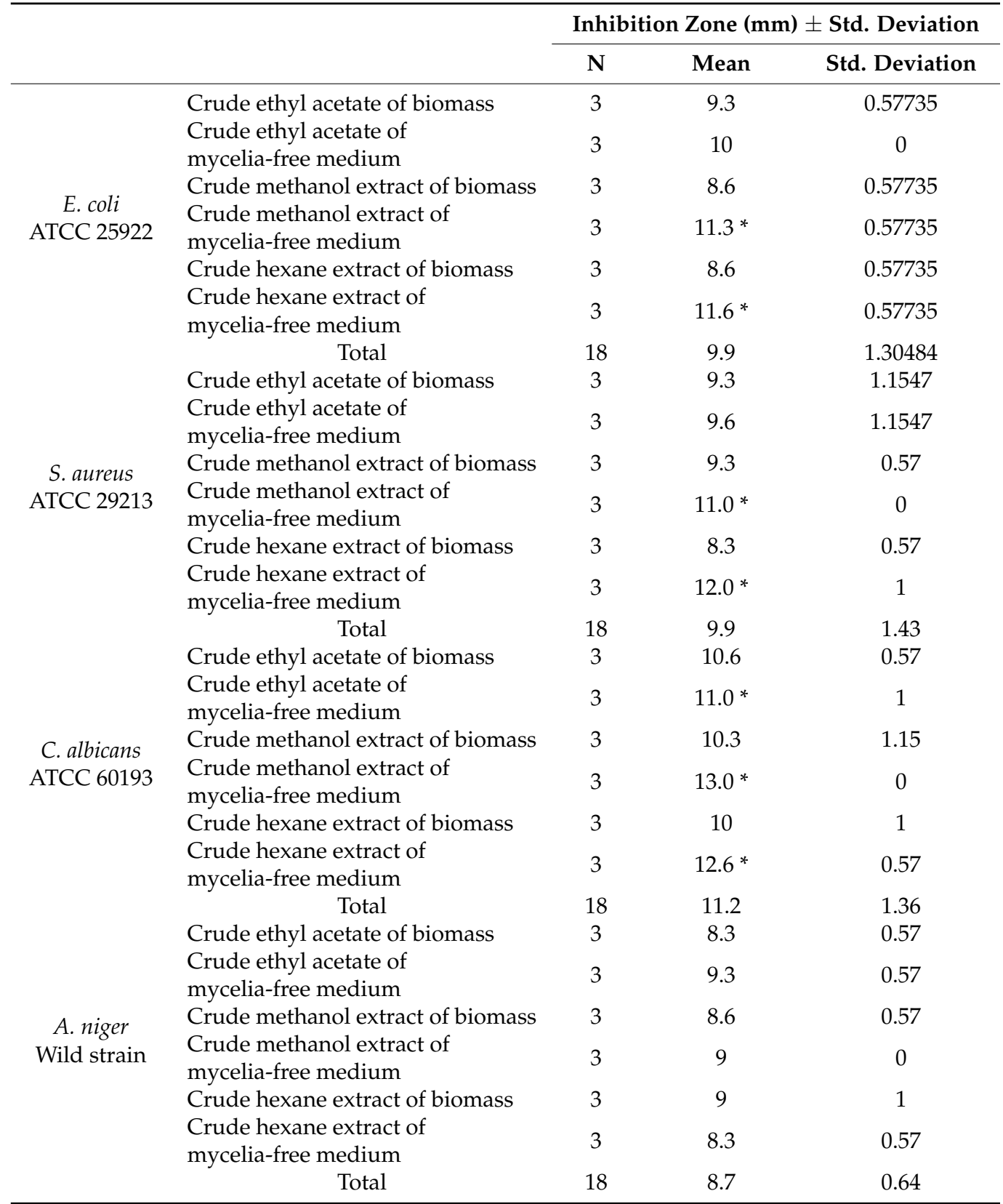

* The means are significantly different $(p<0.05)$ using One-Way ANOVA: Post Hoc multiple comparisons, Tukey test (IBM SPSS, Statistics 25).

\section{Discussion}

This study is the first of its kind to use the ascospores of T. nivea to produce mycelial biomass as a renewable resource of biological compounds. The yield of wet biomass and the compounds detected in fungal-cell free broth are encouraging for the consideration of industrial applications that might depend on this source. The GC-MS analysis of the mycelial biomass and by-products biosynthesized as extracellular compounds in a growth medium (potato dextrose broth) reported that mycelial biomass and its by-products are natural renewable resources of several important biological compounds that have many applications in the medical and industrial fields. The production of biological compounds from the fruiting body of $T$. nivea requires a long period of time and is affected by climate 
change, unlike the current method, in which all production conditions are controlled inside a laboratory.

The preliminary screening of chemical compounds of the crude ethyl acetate of wet mycelia biomass showed that the extract contained the following important biological compounds: hexanal (hexanaldehyde), which is applied in the flavor industry [16]; anthracene, which is used to produce dyes [17]; 8-methyloctahydrocoumarin, which can be used as a coumarin derivative [18]; dodecane, which is used as a solvent and a scintillator [19]; phenol, 2, 4-bis (1,1-dimethylethyl), which has many applications in medication and food [20]; 4-hydroxyphenylacetic acid, ethyl ester and tert-butyl-dimethyl-silyl, which is a 4-hydroxyphenylacetic acid derivative that plays an important role in metabolic reactions in plant, fungi, animals and humans[21]; heptadecane, which is used in the production of essential oils [22]; oleic acid, which has many applications in human and animal food as emulsifying agent and in cosmetics [23]; 1-eicosene, which is used as a monomer to produce several chemical copolymers [24]; hexa-decanoic acid methyl ester, which is an anticancer compound [25]; tetra-decanoic acid (i.e., myristic acid used in cosmetics) [26]; 9,12-octadecadienoic acid and methyl ester (linoleic acid), which is used as a hypocholesterolemic, anticancer and anti-inflammatory agent, among others [27]; and 7-pentadecyne, which is an anticancer compound [25].

Similar biological compounds were extracted using ethyl acetate from both wet mycelia biomass and mycelia-free broth, such as phenol, 2, 4-bis (1,1-dimethylethyl), heptadecane, hexa-decanoic acid methyl ester (which was also found in the crude methanol extract and crude hexane extract of wet mycelia biomass) and 1-eicosene. All the biological compounds listed in Table 2 were detected only in the crude ethyl acetate of wet mycelia biomass, except for the compounds mentioned above and cis-9-octadecenamide (i.e., oleamide, a drug for anxiety disorders) [28], which was also found in the crude hexane extract of wet mycelial biomass. The compounds presented in Table 2 include those that could be used in industrial applications, such as octadecanamide (stearamide) [29,30], stigmasta derivatives [31], 1-octadecene (which has an important role in nanoelectronics production) [32] and methyl decanoate [33].

Table 3 presents the following compounds, also found in other extracts: dodecane (found in crude ethyl acetate), 7-pentadecyne (found in crude ethyl acetate), hexa-decanoic acid methyl ester (found in the crude extract of ethyl acetate and crude hexane extract of wet mycelial biomass), 9,12-octadecadienoic acid (Z,Z)-methyl ester (found in crude ethyl acetate and hexane extracts of wet mycelial biomass), 9-octadecenoic acid (Z)-methyl ester (found in crude ethyl acetate and hexane extracts of wet mycelial biomass), methyl 16-methyl-heptadecanoate (found in the crude hexane extract of mycelium-free medium) and n-hexa-decanoic acid (found in the crude methanol extract of wet mycelial biomass and considered an anti-inflammatory agent [34] and a potential anticancer agent [35].

Regarding all the extracts screened in this work, the results showed that the crude methanol extract of the mycelium-free medium was the only resource of all the biological compounds listed in Table 4, compared with the other crude extracts analyzed in this work. The compounds obtained from the crude methanol extract of the mycelium-free medium have the following biological and industrial applications: antimicrobial and antiviral activities (e.g., 1-Piperidineethanol and its derivatives [36]glutaraldehyde [37], nonanoic acid [38] and dodemorph [39], perfume and flavor industries (e.g., 2,4-dihydroxy2,5-dimethyl-3(2H)-furan-3-one [40] and maltol [41], solvent industry (e.g., 1,3-dimethyl-2imidazolidinone [42], bio-refinery (e.g., methyl 2-furoate [43] and food and public health (e.g., 2-furancarboxaldehyde, 5-(hydroxymethyl) ([44].

The crude hexane extract of wet mycelial biomass (Table 5) was distinguished from the other crude extracts through the presence of the following compounds: 1,5-dimethyl4-allylaminocytosine, $2(1 \mathrm{H})$-quinolinone, 4-phenoxy-, tri-tetracontane, carbonic acid, octadecyl 2,2,2-trichloroethyl ester, phthalic acid, 3-(2-methoxyethyl)heptyl propyl ester, penta-decyl heptafluorobutyrate, cyclohexadecane, 1,2-diethyl-, 2H-1,3-benzimidazol2-one, 5-amino-1,3-dihydro-, 3-buten-2-one, 4-(di-methylamino)-3-(methylamino)-, 11- 
dodecen-1-ol trifluoroacetate, 2-mmethyl-7-nonadecene, E-15-heptadecenal, cyclohexane, 2-propenyl-, estra-1,3,5(10)-trien-17.beta.-ol, cyclohexene, 4-(4-ethylcyclohexyl)-1-pentyl, 1,2-benzenedicarboxylic acid and mono(2-ethylhexyl) ester. Benzimidazole and its derivatives are good examples of the important biological compounds of this extract that can be used in the biochemical synthesis of many antiparasitic [45] and antifungal agents [46].

As shown in Table 6, five compounds found in the crude hexane extract of myceliumfree medium were also found in the crude extracts of hexane (7,9-Di-tert-butyl-1-oxaspiro $(4,5)$ deca-6,9-diene-2,8-dione, p-Menth-8(10)-en-9-ol, cis-, cyclohexane, 1-(1,5-dimethylhexyl)4-(4-methylpentyl), pyridine-3-carboxamide, oxime and $\mathrm{N}$-(2-trifluoromethylphenyl) acid] and methanol (methyl 16-methyl-heptadecanoate)). The crude hexane extract obtained from the mycelium-free medium included many important biological compounds, such as benzene-dicarboxylic acid and its derivatives, which play a role in the perfume and cosmetic industries [27]; phenylacetaldehyde derivatives, which are used in the aroma and flavor industries and have antimicrobial activity [47]; caryophyllenes, which have biological activities as antimicrobial, antioxidant and anti-inflammatory agents $[48,49]$ phthalic acid esters and dibutyl phthalate, which can be used in many products such as plasticizers [50]; pentadecanoic acid, which has biological activity as an anticancer agent [51] ; and cyclo-pentadecane compounds, which have anti-trypanosomal activity for Chagas disease [52].

In industrial mycology, there are two major two forms of applied production, the first from fungal biomass (fungal cells) and the second from metabolic products which are frequently extracted from the cell-fee broth. In the present work, the findings reported significant variety between the compounds detected in mycelia-free broths and fungal biomass for all extracts used. For example, octa-decanamide (which has several industrial applications [30] was extracted using ethyl acetate from fungal cell-free broth but not from fungal cell biomass. The same applies to carbamic acid (whose esters are commonly used as insecticides [53] and its derivates. With respect to crude methanol extracts, for example, the dodemorph (fungicide agent [54] can be produced from the fungal cell-free broth using methanol in the primary extraction stage. Among all extracts obtained in this works, the crude methanol extract obtained from the mycelia-free broth was the only resource of several compounds such as dodemorph, 1-piperidineethanol, and maltol. The same result was repeated with regard to crude hexane extracts, where it was confirmed that fungal cell-free broth is considered a resource of many compounds that are absent from the fungal biomass. For example, caryophyllene, heptacosane, Tetratriacontane, dibutyl phthalate, and docosene.

Thomas et al., [55] reported that there are many industrial applications of Truffles including $T$. nivea. The applications include food, medicinal, and nanoparticles. In general, truffles (for example, $T$. nivea) are considered as one the most important sources of antioxidant agents such as phenolics, $\beta$-carotene, and ascorbic acid [56]. There are several antimicrobial agents detected in this work such as 1-Piperidineethanol and its derivatives (in the crude methanol extract of mycelia-free medium), Benzimidazole (in crude hexane extract of mycelial biomass and its derivatives), and dodemorph (in crude methanol extracts of mycelia-free medium). Some studies have reported that the fruiting body of $T$. nivea contains many antimicrobial agents $[7,11]$ but there no work investigated the biomass produced from ascospores $T$. nivea as a source of potential antimicrobial agents.

\section{Conclusions}

This study investigated the preliminary chemical screening of the major volatile organic compounds of mycelia biomass produced from the ascospores T. nivea and metabolites secreted as extracellular products. The yield of wet mycelium biomass reached about $6 \mathrm{gm}$ per $100 \mathrm{~mL}$ of medium; furthermore the fungal cell-free broth was the source of many important compounds. The findings show that the crude extracts of ethyl acetate, methanol and hexane obtained in this study could be natural renewable resources in several biological activity compounds that play the role of antibacterial, antifungal (for example, 
piperidine-ethanol, benzimidazole, and dodemorph), antiviral, anticancer, antioxidant, anti-trypanosomal and anti-inflammatory agents. The crude hexane and methanol of fungal cell-free broth extracts could be the best source of antimicrobial agents among all tested extracts. In addition, many compounds were found in all the crude extracts that could be used in industrial applications. We suggest confirming the benefits of this novel and renewable resource through small-scale production of its products and further investigation of its biological activity.

Author Contributions: Conceptualization, J.M.K., N.S.A., R.A.M. and S.K.; methodology, J.M.K., S.K. and R.A.M.; software, S.K. and J.M.K.; validation, R.A.M., N.S.A. and J.M.K.; formal analysis, S.K.; investigation, A.S.A.; resources, J.M.K.; data curation, A.S.A.; writing-original draft preparation, J.M.K.; writing-review and editing, S.K.; visualization, R.A.M.; supervision, N.S.A.; project administration, J.M.K.; funding acquisition, N.S.A. All authors have read and agreed to the published version of the manuscript.

Funding: National Plan for Science, Technology and Innovation (MAARIFAH), King Abdulaziz City for Science and Technology, Kingdom of Saudi Arabia, Award Number (0002-001-01-17-2).

Institutional Review Board Statement: Not applicable.

Informed Consent Statement: Not applicable.

Data Availability Statement: Not applicable.

Acknowledgments: This Project was funded by the National Plan for Science, Technology and Innovation (MAARIFAH), King Abdulaziz City for Science and Technology, Kingdom of Saudi Arabia, Award Number (0002-001-01-17-2).

Conflicts of Interest: The authors declare no conflict of interest.

\section{References}

1. Alsheikh, A.; Trappe, J. Desert truffles: The genus Tirmania. Trans. Br. Mycol. Soc. 1983, 81, 83-90. [CrossRef]

2. Díez, J.; Manjón, J.L.; Martin, F. Molecular phylogeny of the mycorrhizal desert truffles (Terfezia and Tirmania), host specificity and edaphic tolerance. Mycologia 2002, 94, 247-259. [CrossRef] [PubMed]

3. Bradai, L.; Neffar, S.; Amrani, K.; Bissati, S.; Chenchouni, H. Ethnomycological survey of traditional usage and indigenous knowledge on desert truffles among the native Sahara Desert people of Algeria. J. Ethnopharmacol. 2015, 162, 31-38. [CrossRef] [PubMed]

4. Hamza, A.; Jdir, H.; Zouari, N. Nutritional, antioxidant and antibacterial properties of Tirmania nivea, a wild edible desert truffle from Tunisia arid zone. Med. Aromat. Plants 2016, 5, 2167-0412. [CrossRef]

5. Omer, E.; Smith, D.; Wood, K.; El-Menshawi, B. The volatiles of desert truffle: Tirmania nivea. Plant Foods Hum. Nutr. 1994, 45, 247-249. [CrossRef] [PubMed]

6. Al-Laith, A.A.A. Antioxidant components and antioxidant/antiradical activities of desert truffle (Tirmania nivea) from various Middle Eastern origins. J. Food Compos. Anal. 2010, 23, 15-22. [CrossRef]

7. Veeraraghavan, V.P.; Hussain, S.; Papayya Balakrishna, J.; Dhawale, L.; Kullappan, M.; Mallavarapu Ambrose, J.; Krishna Mohan, S. A Comprehensive and Critical Review on Ethnopharmacological Importance of Desert Truffles: Terfezia claveryi, Terfezia boudieri, and Tirmania nivea. Food Rev. Int. 2021, 1-20. [CrossRef]

8. Dib-Bellahouel, S.; Fortas, Z. Antibacterial activity of various fractions of ethyl acetate extract from the desert truffle, Tirmania pinoyi, preliminarily analyzed by gas chromatography-mass spectrometry (GC-MS). Afr. J. Biotechnol. 2011, 10, 9694-9699. [CrossRef]

9. Elsayed, E.; Alsahli, F.; El Enshasy, H.; Wadaan, M. Cytotoxic Activities of Different Solvent Extracts of Tirmania nivea and Terfezia claveryi against HepG2 and L929 Cells. J. Sci. Ind. Res. 2019, 78, 454-457.

10. Muhsin, T.M.; Hachim, A.K. Characterization and Antibacterial Efficacy of Mycosynthesized Silver Nanoparticles from the Desert Truffle Tirmania nivea. In Qatar Foundation Annual Research Conference Proceedings Volume 2016 Issue 1; Hamad bin Khalifa University Press: Ar Rayyan, Qatar, 2016; Volume 2016, p. HBPP1362.

11. Darwish, R.S.; Shawky, E.; Nassar, K.M.; ElSayed, R.M.R.; Hussein, D.E.; Ghareeb, D.A.; El Sohafy, S.M. Differential antiinflammatory biomarkers of the desert truffles Terfezia claveryi and Tirmania nivea revealed via UPLC-QqQ-MS-based metabolomics combined to chemometrics. LWT 2021, 150, 111965. [CrossRef]

12. Chauhan, O.P.; Vijay, V.; Pandey, A.K.; Semwal, A.D. Biochemical and Health Properties of Truffles. Def. Life Sci. J. 2021, 6, 251-258. [CrossRef]

13. Arenas, F.; Navarro-Ródenas, A.; Chávez, D.; Gutiérrez, A.; Pérez-Gilabert, M.; Morte, A. Mycelium of Terfezia claveryi as inoculum source to produce desert truffle mycorrhizal plants. Mycorrhiza 2018, 28, 691-701. [CrossRef] 
14. Desbois, A.P.; Smith, V.J. Disk diffusion assay to assess the antimicrobial activity of marine algal extracts. In Natural Products From Marine Algae; Humana Press: New York, NY, USA, 2015; pp. 403-410.

15. Khadka, S.; Sherchand, J.B.; Pokhrel, B.M.; Dhital, S.; Manjhi, R.; Rijal, B. Antifungal susceptibility testing of dermatophytes by agar based disk diffusion assay in Tertiary Care Hospital, Nepal. Microbiol. Res. J. Int. 2017, 19, 1-5. [CrossRef]

16. Kryger, R.A. Regulatory Issues and Flavors Analysis. In Practical Analysis of Flavor and Fragrance Material; Blackwell Publishing Ltd.: Hoboken, NJ, USA, 2011.

17. Shen, T.; Zhao, Z.-G.; Yu, Q.; Xu, H.-J. Photosensitized reduction of benzil by heteroatom-containing anthracene dyes. J. Photochem. Photobiol. A Chem. 1989, 47, 203-212. [CrossRef]

18. Weigt, S.; Huebler, N.; Strecker, R.; Braunbeck, T.; Broschard, T.H. Developmental effects of coumarin and the anticoagulant coumarin derivative warfarin on zebrafish (Danio rerio) embryos. Reprod. Toxicol. 2012, 33, 133-141. [CrossRef] [PubMed]

19. Zheng, Z.; Zhu, J.; Luo, X.; Xu, Y.; Zhang, Q.; Zhang, X.; Bi, Y.; Zhang, L. Preparation and performance study of a novel liquid scintillator with mixed solvent as the matrix. Nucl. Instrum. Methods Phys. Res. Sect. A Accel. Spectrometers Detect. Assoc. Equip. 2017, 850, 12-17. [CrossRef]

20. Ren, J.; Wang, J.; Karthikeyan, S.; Liu, H.; Cai, J. Natural anti-phytopathogenic fungi compound phenol, 2,4-bis (1,1-dimethylethyl) from Pseudomonas fluorescens TL-1. Indian J. Biochem. Biophys. (IJBB) 2019, 56, 162-168.

21. Adachi, K.; Takeda, Y.; Senoh, S.; Kita, H. Metabolism of p-hydroxyphenylacetic acid in Pseudomonas ovalis. Biochim. Biophys. Acta (BBA)-Gen. Subj. 1964, 93, 483-493. [CrossRef]

22. Jiao, J.; Ma, D.-H.; Gai, Q.-Y.; Wang, W.; Luo, M.; Fu, Y.-J.; Ma, W. Rapid analysis of Fructus forsythiae essential oil by ionic liquidsassisted microwave distillation coupled with headspace single-drop microextraction followed by gas chromatography-mass spectrometry. Anal. Chim. Acta 2013, 804, 143-150. [CrossRef]

23. Acid, L. Final report on the safety assessment of oleic acid, laurie acid, palmitic acid, myristic acid, and stearic acid. J. Am. Coll. Toxicol. 1987, 6, 321-401.

24. Coxon, G.D.; Douglas, J.D.; Minnikin, D.E. Facile synthesis of (Z)-tetracos-5-enoic acid and racemic cis-4-(2-octadecylcyclopropane1-yl)-butanoic acid. Chem. Phys. Lipids 2003, 126, 49-53. [CrossRef]

25. Sianipar, N.F.; Purnamaningsih, R.; Darwati, I.; Laurent, D. Gas chromatography-mass spectrometry (GC-MS) analysis of phytochemicals of first generation gamma-irradiated Typhonium flagelliforme lodd. Mutants. J. Teknol. 2016, 78. [CrossRef]

26. Becker, L.C.; Bergfeld, W.F.; Belsito, D.V.; Hill, R.A.; Klaassen, C.D.; Marks, J.G.; Shank, R.C.; Slaga, T.J.; Snyder, P.W.; Andersen, F.A. Final report of the amended safety assessment of myristic acid and its salts and esters as used in cosmetics. Int. J. Toxicol. 2010, 29, 162S-186S. [CrossRef] [PubMed]

27. Roy, P.; Amdekar, S.; Kumar, A.; Singh, V. Preliminary study of the antioxidant properties of flowers and roots of Pyrostegia venusta (Ker Gawl) Miers. BMC Complement. Altern. Med. 2011, 11, 1-8. [CrossRef] [PubMed]

28. Geracioti Jr, T.D.; Kasckow, J.W. Methods of Treating Anxiety and Mood Disorders with Oleamide. U.S. Patent US6,359,010, 19 March 2002.

29. Briscoe, B.; Mustafaev, V.; Tabor, D. Lubrication of polythene by oleamide and stearamide. Wear 1972, 19, 399-414. [CrossRef]

30. Zhang, X.; He, J.-X.; Huang, G.; Zhou, C.; Feng, M.-M.; Li, Y. Preparation and characteristics of ethylene bis (stearamide)-based graphene-modified asphalt. Materials 2019, 12, 757. [CrossRef]

31. Bonveh, J.S.; Torrent, M.S.; Coll, F.V. A laboratory study of the bleaching process in stigmasta-3, 5-diene concentration in olive oils. J. Am. Oil Chem. Soc. 2001, 78, 305-310. [CrossRef]

32. Antonova, I.; Soots, R.; Seleznev, V.; Prints, V.Y. Electrical passivation of the silicon surface by organic monolayers of 1-octadecene. Semiconductors 2007, 41, 991-997. [CrossRef]

33. Herbinet, O.; Glaude, P.-A.; Warth, V.; Battin-Leclerc, F. Experimental and modeling study of the thermal decomposition of methyl decanoate. Combust. Flame 2011, 158, 1288-1300. [CrossRef]

34. Aparna, V.; Dileep, K.V.; Mandal, P.K.; Karthe, P.; Sadasivan, C.; Haridas, M. Anti-inflammatory property of n-hexadecanoic acid: Structural evidence and kinetic assessment. Chem. Biol. Drug Des. 2012, 80, 434-439. [CrossRef]

35. Ravi, L.; Krishnan, K. Research Article Cytotoxic Potential of N-hexadecanoic Acid Extracted from Kigelia pinnata Leaves. Asian J. Cell Biol 2017, 12, 20-27. [CrossRef]

36. Gamzaeva, S.; Mamedova, P.S.; Allakhverdieva, K.; Velieva, G.K.; Akhundova, M.; Allakhverdiev, M. A study of 2-piperidino-1ethanol and its derivatives as antimicrobial additives to oils. Russ. J. Appl. Chem. 2009, 82, 1577-1581. [CrossRef]

37. Russell, A. Glutaraldehyde: Current status and uses. Infect. Control Hosp. Epidemiol. 1994, 15, 724-733. [CrossRef] [PubMed]

38. Jang, Y.-W.; Jung, J.-Y.; Lee, I.-K.; Kang, S.-Y.; Yun, B.-S. Nonanoic acid, an antifungal compound from Hibiscus syriacus Ggoma. Mycobiology 2012, 40, 145-146. [CrossRef] [PubMed]

39. Lamberth, C.; Rendine, S.; Sulzer-Mosse, S. Agrochemical disease control: The story so far. In Recent Highlights in the Discovery and Optimization of Crop Protection Products; Academic Press: Cambridge, MA, USA, 2021; pp. 65-85.

40. Zabetakis, I.; Gramshaw, J.; Robinson, D. 2,5-Dimethyl-4-hydroxy-2H-furan-3-one and its derivatives: Analysis, synthesis and biosynthesis-A review. Food Chem. 1999, 65, 139-151. [CrossRef]

41. Zhang, G.; Ma, Y.; Wang, L.; Zhang, Y.; Zhou, J. Multispectroscopic studies on the interaction of maltol, a food additive, with bovine serum albumin. Food Chem. 2012, 133, 264-270. [CrossRef]

42. Lo, C.-C.; Chao, P.-M. Replacement of carcinogenic solvent HMPA by DMI in insect sex pheromone synthesis. J. Chem. Ecol. 1990, 16, 3245-3253. [CrossRef] 
43. Manzoli, M.; Menegazzo, F.; Signoretto, M.; Marchese, D. Biomass derived chemicals: Furfural oxidative esterification to methyl-2-furoate over gold catalysts. Catalysts 2016, 6, 107. [CrossRef]

44. Choudhary, A.; Kumar, V.; Kumar, S.; Majid, I.; Aggarwal, P.; Suri, S. 5-Hydroxymethylfurfural (HMF) formation, occurrence and potential health concerns: Recent developments. Toxin Rev. 2020, 40, 1-17. [CrossRef]

45. Florio, R.; Carradori, S.; Veschi, S.; Brocco, D.; Di Genni, T.; Cirilli, R.; Casulli, A.; Cama, A.; De Lellis, L. Screening of Benzimidazole-Based Anthelmintics and Their Enantiomers as Repurposed Drug Candidates in Cancer Therapy. Pharmaceuticals 2021, 14, 372. [CrossRef]

46. Malandrakis, A.A.; Kavroulakis, N.; Chrysikopoulos, C.V. Copper nanoparticles against benzimidazole-resistant Monilinia fructicola field isolates. Pestic. Biochem. Physiol. 2021, 173, 104796. [CrossRef]

47. Jay, J.; Rivers, G. Antimicrobial activity of some food flavoring compounds [21 compounds tested against Pseudomonas fluorescens, Pseudomonas geniculata]. J. Food Saf. 1984, 6, 129-139. [CrossRef]

48. Dahham, S.S.; Tabana, Y.M.; Iqbal, M.A.; Ahamed, M.B.; Ezzat, M.O.; Majid, A.S.; Majid, A.M. The anticancer, antioxidant and antimicrobial properties of the sesquiterpene $\beta$-caryophyllene from the essential oil of Aquilaria crassna. Molecules 2015, 20, 11808-11829. [CrossRef]

49. Li, W.-Y.; Yang, F.; Chen, J.-H.; Ren, G.-F. $\beta$-Caryophyllene Ameliorates MSU-Induced Gouty Arthritis and Inflammation Through Inhibiting NLRP3 and NF-kB Signal Pathway: In Silico and In Vivo. Front. Pharmacol. 2021, 12, 951. [CrossRef] [PubMed]

50. Caldeirão, L.; Fernandes, J.O.; da Silva Oliveira, W.; Godoy, H.T.; Cunha, S.C. Phthalic acid esters and adipates in herbal-based soft drinks: An eco-friendly method. Anal. Bioanal. Chem. 2021, 413, 2903-2912. [CrossRef] [PubMed]

51. To, N.B. Pentadecanoic Acid as a Novel Anti-Cancer Agent in Human Breast Cancer Stem-Like MCF-7/SC cells. 2021. Available online: https:/ / oak.jejunu.ac.kr/handle/2020.oak/23499 (accessed on 16 November 2021).

52. Nakashima, T.; Iwatsuki, M.; Ochiai, J.; Kamiya, Y.; Nagai, K.; Matsumoto, A.; Ishiyama, A.; Otoguro, K.; Shiomi, K.; Takahashi, Y. Mangromicins A and B: Structure and antitrypanosomal activity of two new cyclopentadecane compounds from Lechevalieria aerocolonigenes K10-0216. J. Antibiot. 2014, 67, 253-260.

53. Riyaz, M.; Mathew, P.; Zuber, S.; Rather, G.A. Botanical Pesticides for an Eco-Friendly and Sustainable Agriculture: New Challenges and Prospects. In Sustainable Agriculture; Springer: Cham, Switzerland, 2022; pp. 69-96.

54. Leenheers, L.; Ravensberg, J.; Kerstens, H.; Jongen, M. Gas chromatographic determination of the pesticide dodemorph for assessment of occupational exposure. J. Chromatogr. Sci. 1992, 30, 228-232. [CrossRef] [PubMed]

55. Thomas, P.; Elkhateeb, W.; Daba, G. Industrial Applications of Truffles and Truffle-like Fungi. In Advances in Macrofungi; CRC Press: Boca Raton, FL, USA, 2021; pp. 82-88.

56. Yousif, P.A.; Jalal, A.F.; Faraj, K.A. Essential Constituents of Truffle in Kurdistan Region. Zanco J. Pure Appl. Sci. 2020, 32, 158-166. 